\title{
Prezados Leitores,
}

Já se passaram seis meses, desde o lançamento da nossa publicação, e, portanto, é com a imensa satisfação que trazemos ao mercado da informação, o novo número da Revista Digital de Biblioteconomia e Ciência da Informação, correspondente ao volume 1 , número 2 de janeiro de 2004. Além dos Artigos, neste número, inauguramos mais uma nova seção da revista, a seção Recensão.

$\mathrm{Na}$ seção de Artigos apresentamos o trabalho "Gestão de processos em Bibliotecas" das autoras Margarida Maria de Oliveira Reis e Ursula Blattmann, respectivamente, mestranda e professora, da Universidade Federal de Santa Catarina. Neste artigo enfocam reflexões que visam contribuir no gerenciamento de tecnologias da informação e comunicação em bibliotecas, apresentando conceitos e características sobre gestão de processos nas organizações com a finalidade de proporcionar uma visão da importância dos processos, do gerenciamento de processos, da gestão da informação, dos serviços e dos produtos de informação em bibliotecas.

Silas Marques de Oliveira, professor da PUC-Campinas, traz o artigo sobre "Fontes de informação utilizadas por executivos". Neste trabalho, o autor discute o papel dos sistemas de informação (SI) nas empresas, e apresenta as fontes de informação internas e externas mais utilizadas na opinião de 45 gerentes de SI que participaram de um estudo de campo.

No terceiro artigo intitulado "As contradições da sociedade da informação e a formação do bibliotecário", de autoria de César Augusto de Castro, professor da Universidade Federal do Maranhão e da bibliotecária da Universidade Estadual de Campinas e também professora orientadora do PEC/USP, Maria Solange Pereira Ribeiro, norteiam duas questões destacadas no próprio título do artigo: as contradições da sociedade da informação e a formação do chamado profissional da informação. Assim, fazem uma reflexão em dois momentos que se completam. Os autores procuram apontar o papel que o bibliotecário assumiu na sociedade brasileira, e em seguida, reportam-se destacando à maneira de como pensamos o papel político e social do bibliotecário na sociedade.

No artigo seguinte, intitulado de "Serviços de apoio a distância ao professor em sala de aula pela TV Digital Interativa", Sérgio Ferreira do Amaral, professor da Faculdade de Educação da Universidade Estadual de Campinas e os diretores técnicos de serviço do CPqD Telecom \& IT Solutions: Luciana Ozello Baratti, Daniel Moutinho Bataca, João Henrique de Augustinis Franco, José Manuel Martin Rios e Amilton da Costa Lamas, apresentam um projeto em andamento, que objetiva estabelecer um serviço de apoio a distância aos professores em sala de aula em 03 escolas da região de Barão Geraldo em Campinas, para utilizar a TV Digital Interativa (TVDI) como ferramenta (tecnológica informacional) de busca e desenvolvimento de conteúdo multimídia interativo nas práticas pedagógicas.

Rev. dig. Bibliotecon. \& Ci Inf., v. 1, n. 2, jan./jun. 2004 [ISSN: 1678-765X] 
No quinto artigo, "Bibliotheca Alexandrina", de autoria de Eliana Serrão Alves Mey, professora do Departamento de Ciência da Informação da Universidade Federal de São Carlos, apresenta-se uma conclusão através de um relato sumário sobre a revivescência e as principais características da nova Bibliotheca Alexandrina, sobre o estabelecimento de um paralelo entre a antiga biblioteca e a nova, como símbolos de conhecimento e coexistência entre diferentes seres humanos e suas perspectivas.

Na seção Recensão Murilo Bastos da Cunha, professor do Departamento de Ciência da Informação da Universidade de Brasília, faz comentários sobre a obra de Jennifer Rowley - A biblioteca eletrônica, publicada pela editora Briquet de Lemos Livros, segunda edição de 2002.

Ainda nesta mesma seção, temos Ezequiel Theodoro da Silva, professor da Faculdade de Educação da Universidade Estadual de Campinas, o qual comenta sobre a obra de Maria Inês Ghilardi e Waldir Heitor Barzotto - Nas telas da mídia, publicada pelas editoras Alínea e ALB, em 2002.

Ainda nesta mesma seção, temos Ezequiel Theodoro da Silva, professor da Faculdade de Educação da Universidade Estadual de Campinas, o qual comenta sobre a obra de Maria Inês Ghilardi e Waldir Heitor Barzotto - Nas telas da mídia, publicada pelas editoras Alínea e ALB, em 2002.

O Conselho Editorial da Revista Digital de Biblioteconomia e Ciência da Informação juntamente com seus editores esperam que vocês, leitores, aproveitem as contribuições da leitura dos artigos e recensões deste número.

Gildenir Carolino Santos gilbfe@unicamp.br

Danielle Thiago Ferreira danif@unicamp.br

Leonardo Fernandes Souto Ifsouto@unicamp.br

Editores-responsáveis pela RDBCI

Rev. dig. Bibliotecon. \& Ci Inf., v. 1, n. 2, jan./jun. 2004 [ISSN: 1678-765X] 